Media Informatika, Vol. 2, No. 2, Desember 2004, 57-64

ISSN: 0854-4743

\title{
PENENTUAN LOKASI PEMANCAR TELEVISI MENGGUNAKAN FUZZY MULTI CRITERIA DECISION MAKING
}

\author{
Sri Kusumadewi \\ Jurusan Teknik Informatika, Fakultas Teknologi Industri,Universitas Islam Indonesia \\ Jl. Kaliurang Km. 14 Yogyakarta 55501 \\ Telp. (0274) 895287 ext. 122, Faks. (0274) 895007 ext. 148 \\ E-mail: cicie@fti.uii.ac.id
}

\begin{abstract}
ABSTRAK
Multi Criteria Decision Making adalah salah satu metode yang bisa membantu pengambil keputusan dalam melakukan pengambilan keputusan terhadap beberapa alternatif keputusan yang harus diambil dengan beberapa kriteria yang akan menjadi bahan pertimbangan. Pada penelitian ini akan digunakan Fuzzy Multi Criteria Decision Making (FMCDM) untuk menentukan lokasi penempatan pemancar televisi dengan beberapa kriteria, yaitu ketinggian lokasi, ketidakpadatan bangunan di sekitar lokasi, kedekatan dari pusat kota, kondisi keamanan lokasi, dan kedekatan dengan pemancar lain yang sudah ada. Ada 3 alternatif lokasi yang diberikan adalah Kota Baru, Kaliurang, dan Piyungan. Dari hasil penelitian diperoleh hasil, Piyungan sebagai alternatif terbaik.
\end{abstract}

Kata kunci: kriteria, alternatif, Fuzzy Multi Criteria Decision Making (FMCDM)

\section{PENGANTAR}

Masalah pengambilan keputusan, memegang peranan yang sangat penting di berbagai segi kehidupan. Selama ini, ada beberapa metode yang telah digunakan sebagai alat bantu dalam pendukung keputusan. Multi Criteria Decision Making adalah salah satu metode yang bisa membantu pengambil keputusan dalam melakukan pengambilan keputusan terhadap beberapa alternatif keputusan yang harus diambil dengan beberapa kriteria yang akan menjadi bahan pertimbangan.

Satu hal yang menjadi permasalahan adalah apabila bobot kepentingan dari setiap kriteria dan derajat kecocokan setiap alternatif terhadap setiap kriteria mengandung ketidakpastian. Biasanya penilaian yang diberikan oleh pengambil keputusan dilakukan secara kualitatif dan direpresentatikan secara linguistik. Salah satu cara yang bisa digunakan untuk mengatasi ketidakpastian adalah dengan menggunakan logika fuzzy. Dalam kaitannya dengan pengambilan keputusan dari beberapa alternatif dengan banyak kriteria, serta informasi yang diberikan bersifat kualitatif, maka pada penelitian ini akan dicoba untuk menggunakan metode Fuzzy Multi-Criteria Decision Making. 
Kasus yang akan diselesaikan pada penelitian ini adalah penentuan lokasi pemancar bagi suatu stasiun televisi di Yogyakarta. Ada 3 lokasi yang akan menjadi alternatif, yaitu: Kota Baru, Kaliurang, dan Piyungan. Pemilihan lokasi dilakukan dengan mempertimbangkan 5 kriteria pengambilan keputusan, yaitu: ketinggian lokasi, ketidakpadatan bangunan di sekitar lokasi; kedekatan dari pusat kota; kondisi keamanan lokasi; dan kedekatan dengan pemancar lain yang sudah ada.

\section{TUJUAN PENELITIAN}

Penelitian ini bertujuan untuk menentukan lokasi penempatan pemancar televisi dengan beberapa kriteria, menggunakan Metode Fuzzy Multi Criteria Decision Making (FMCDM).

\section{DASAR TEORI}

Pada Metode Fuzzy Decision Making (FDM), ada 3 langkah penting yang harus dikerjakan, yaitu: representasi masalah, evaluasi himpunan fuzzy pada setiap alternatif keputusan, dan melakukan seleksi terhadap alternatif yang optimal (Joo HM dan Chang, 2004).

\subsection{Representasi Masalah}

Pada bagian, ada 3 aktivitas yang harus dilakukan, yaitu:

a. Identifikasi tujuan dan kumpulan alternatif keputusannya;

Tujuan keputusan dapat direpresentasikan dengan menggunakan bahasa alami atau nilai numeris sesuai dengan karakteristik dari masalah tersebut. Jika ada $\mathrm{n}$ alternatif keputusan dari suatu masalah, maka alternatif-alternatif tersebut dapat ditulis sebagai $A=\left\{A_{i} \mid i=1,2, \ldots, n\right\}$.

b. Identifikasi kumpulan kriteria;

Jika ada k kriteria, maka dapat dituliskan $C=\left\{C_{t} \mid t=1,2, \ldots, k\right\}$.

c. Membangun stuktur hirarki dari masalah tersebut berdasarkan pertimbanganpertimbangan tertentu.

Struktur hirarki ini dapat dilihat pada Gambar 1. 


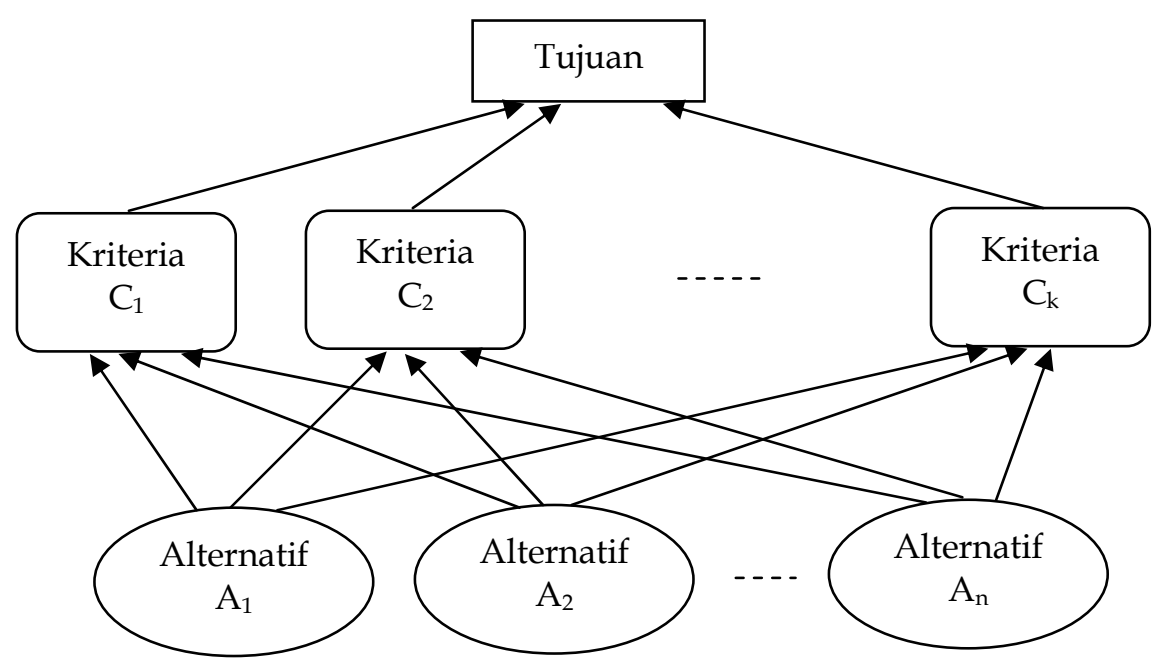

Gambar 1. Struktur hirarki

\subsection{Evaluasi Himpunan Fuzzy}

Pada bagian ini, ada 3 aktivitas yang harus dilakukan, yaitu:

a. Memilih himpunan rating untuk bobot-bobot kriteria, dan derajat kecocokan setiap alternatif dengan kriterianya;

Secara umum, himpunan-himpunan rating terdiri-atas 3 elemen, yaitu: variabel linguistik $(\mathrm{x})$ yang merepresentasikan bobot kriteria, dan derajat kecocokan setiap alternatif dengan kriterianya; $\mathrm{T}(\mathrm{x})$ yang merepresentasikan rating dari variabel linguistik; dan fungsi keanggotaan yang berhubungan dengan setiap elemen dari $\mathrm{T}(\mathrm{x})$. Misal, rating untuk bobot pada Variabel Penting untuk suatu kriteria didefinisikan sebagai: $T$ (penting) $=\{$ SANGAT RENDAH, RENDAH, CUKUP, TINGGI, SANGAT TINGGI\}.

Sesudah himpunan rating ini ditentukan, maka kita harus menentukan fungsi keanggotaan untuk setiap rating. Biasanya digunakan fungsi segitiga, sebagai berikut:

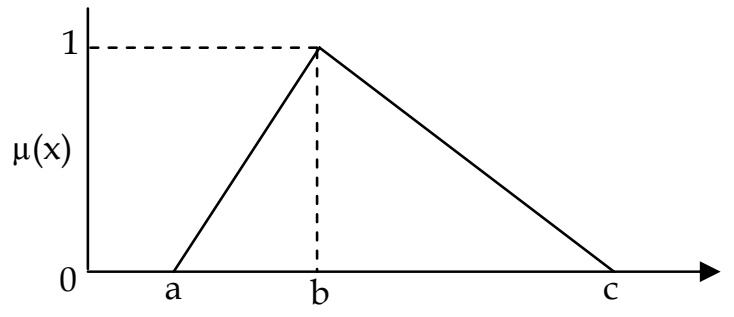

Gambar 2. Bilangan fuzzy segitiga 


$$
\mu(x)= \begin{cases}\frac{(x-a)}{(b-a)} ; & a \leq x \leq b \\ \frac{(x-c)}{(b-c)} ; & b \leq x \leq c \\ 0 ; & x \leq b \text { atau } x \geq c\end{cases}
$$

Misal, $\mathrm{W}_{\mathrm{t}}$ adalah bobot untuk kriteria $\mathrm{C}_{\mathrm{t}}$; dan $\mathrm{S}_{\mathrm{it}}$ adalah rating fuzzy untuk derajat kecocokan alternatif keputusan $A_{i}$ dengan kriteria $C_{t}$; dan $F_{i}$ adalah indeks kecocokan fuzzy dari alternatif $A_{i}$ yang merepresentasikan derajat kecocokan alternatif keputusan dengan kriteria keputusan yang diperoleh dari hasil agregasi $S_{\text {it }}$ dan $W_{t}$. (Chang dan Chen, 1994)

b. Mengevaluasi bobot-bobot kriteria, dan derajat kecocokan setiap alternatif dengan kriterianya;

c. Mengagregasikan bobot-bobot kriteria, dan derajat kecocokan setiap alternatif dengan kriterianya.

Ada beberapa metode yang dapat digunakan untuk melakukan agregasi terhadap hasil keputusan para pengambil keputusan, antara lain: mean, median, max, min, dan operator campuran. Dari beberapa metode tersebut, metode mean yang paling banyak digunakan. Operator $\oplus$ dan $\otimes$ adalah operator yang digunakan untuk penjumlahan dan perkalian fuzzy. Dengan menggunakan operator mean, $\mathrm{F}_{\mathrm{i}}$ dirumuskan sebagai:

$$
F_{i}=\left(\frac{1}{k}\right)\left[\left(S_{i 1} \otimes W_{1}\right) \oplus\left(S_{i 2} \otimes W_{2}\right) \oplus \cdots \oplus\left(S_{i k} \otimes W_{k}\right)\right]
$$

Dengan cara mensubstitusikan $S_{i t}$ dan $W_{t}$ dengan bilangan fuzzy segitiga, yaitu $S_{i t}=\left(o_{i t}, p_{i t}, q_{i t}\right)$; dan $W_{t}=\left(a_{t}, b_{t}, c_{t}\right)$; maka $F_{t}$ dapat didekati sebagai:

$F_{i} \cong\left(Y_{i}, Q_{i}, Z_{i}\right)$

dengan:

$$
\begin{aligned}
& Y_{i}=\left(\frac{1}{k}\right) \sum_{t=1}^{k}\left(o_{i t} a_{i}\right) \\
& Q_{i}=\left(\frac{1}{k}\right) \sum_{t=1}^{k}\left(p_{i t} b_{i}\right) \\
& Z_{i}=\left(\frac{1}{k}\right) \sum_{t=1}^{k}\left(q_{i t} c_{i}\right) \\
& \mathrm{i}=1,2, \ldots, \mathrm{n} .
\end{aligned}
$$




\subsection{Seleksi Alternatif yang Optimal}

Pada bagian ini, ada 2 aktivitas yang dilakukan, yaitu:

a. Memprioritaskan alternatif keputusan berdasarkan hasil agregasi;

Prioritas dari hasil agregasi dibutuhkan dalam rangka proses perangkingan alternatif keputusan. Karena hasil agregasi ini direpresentasikan dengan menggunakan bilangan fuzzy segitiga, maka dibutuhkan metode perangkingan untuk bilangan fuzzy segitiga (Chen, 1985, Kim dan Park, 1990, Liou dan Wang, 1992). Salah satu metode yang dapat digunakan adalah metode nilai total integral. Misalkan F adalah bilangan fuzzy segitiga, $F=(a, b, c)$, maka nilai total integral dapat dirumuskan sebagai berikut (Liou dan Wang, 1992):

$I_{T}^{\alpha}(F)=\left(\frac{1}{2}\right)(\alpha c+b+(1-\alpha) a)$

Nilai $\alpha$ adalah indeks keoptimisan yang merepresentasikan derajat keoptimisan bagi pengambil keputusan $(0 \leq \alpha \leq 1)$. Apabila nilai $\alpha$ semakin besar mengindikasikan bahwa derajat keoptimisannya semakin besar.

b. Memilih alternatif keputusan dengan prioritas tertinggi sebagai alternatif yang optimal.

Semakin besar nilai $F_{i}$ berarti kecocokan terbesar dari alternatif keputusan untuk kriteria keputusan, dan nilai inilah yang akan menjadi tujuannya.

\section{METODOLOGI PENELITIAN}

Penelitian dilakukan melalui langkah-langkah sebagai berikut:

a. Representasi masalah, meliputi: penetapan tujuan keputusan, identifikasi alternatif, identifikasi kriteria, dan membangun struktur hirarki keputusan.

b. Evaluasi himpunan fuzzy dari alternatif-alternatif keputusan, meliputi: menetapkan variabel linguistik dan fungsi keanggotaan, menetapkan rating untuk setiap kriteria, dan menghitung indeks kecocokan fuzzy pada setiap alternatif.

c. Melakukan defuzzy dalam rangka mencari nilai alternatif yang optimal.

\section{HASIL PENELITIAN}

Suatu stasiun televisi di Yogyakarta ingin menempatkan pemancarnya pada suatu lokasi. Ada 3 lokasi yang akan menjadi alternatif, yaitu: S1 = Kota Baru, S2 = Kaliurang, dan S3 = Piyungan. Ada 5 atribut (kriteria) pengambilan keputusan, yaitu: $\mathrm{C} 1$ = ketinggian lokasi, $\mathrm{C} 2$ = ketidakpadatan bangunan di sekitar lokasi; C3 = kedekatan dari pusat kota; $\mathrm{C} 4=$ kondisi keamanan lokasi ; C5 = kedekatan dengan pemancar lain yang sudah ada.. 


\section{Langkah 1: Representasi masalah}

a. Tujuan keputusan ini adalah mencari lokasi terbaik untuk menempatkan pemancar televisi berdasarkan kriteria-kriteria tertentu. Ada 3 alternatif lokasi yang diberikan adalah $\mathrm{A}=\{\mathrm{A} 1, \mathrm{~A} 2, \mathrm{~A} 3\}$, dengan $\mathrm{A} 1=$ Kota Baru, $\mathrm{A} 2=$ Kaliurang, A3 = Piyungan.

b. Ada 5 kriteria keputusan yang diberikan, yaitu: $C=\{C 1, C 2, C 3, C 4, C 5\}$

c. Struktur hirarki masalah tersebut seperti terlihat pada Gambar 3

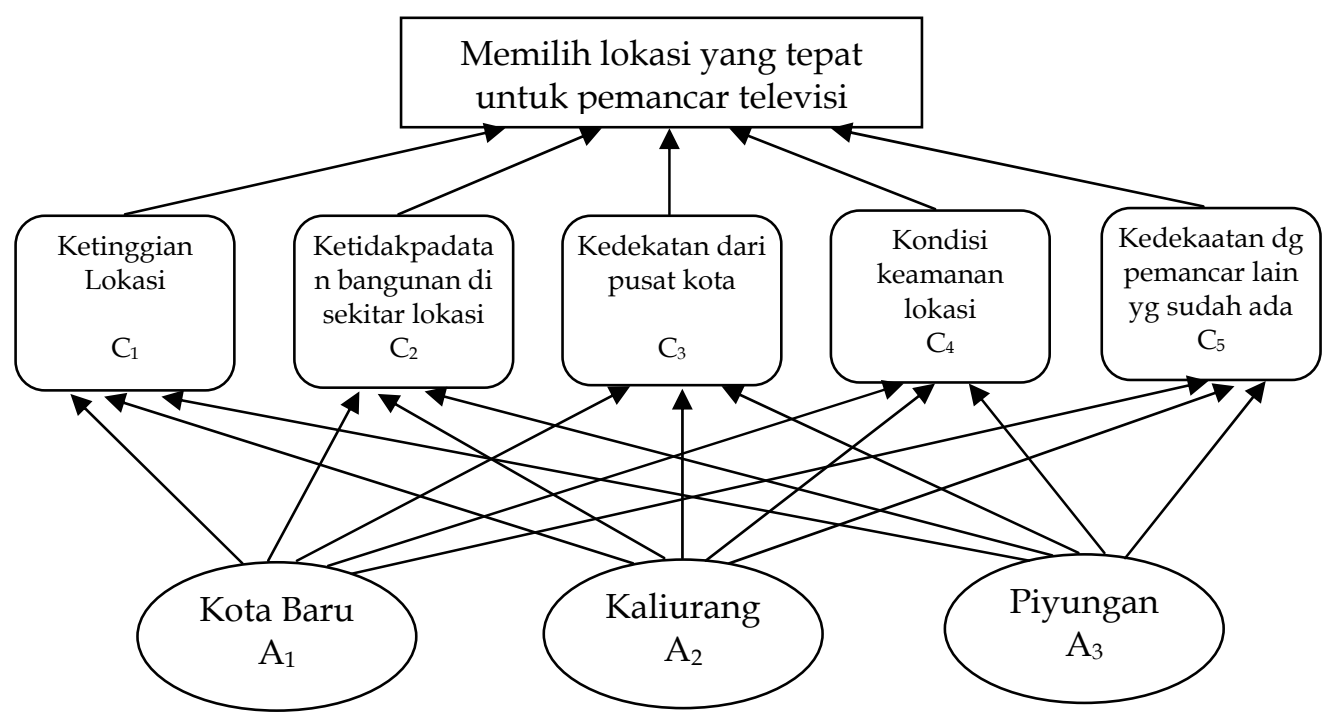

Gambar 3 Struktur hirarki Kasus.

\section{Langkah 2: Evaluasi himpunan fuzzy dari alternatif-alternatif keputusan}

a. Variabel-variabel linguistik yang merepresentasikan bobot kepentingan untuk setiap kriteria, adalah: $\mathrm{T}$ (kepentingan) $\mathrm{W}=\{\mathrm{SR}, \mathrm{R}, \mathrm{C}, \mathrm{T}, \mathrm{ST}\}$ dengan $\mathrm{SR}=$ Sangat Rendah; $\mathrm{R}=$ Rendah; $\mathrm{C}=$ Cukup; $\mathrm{T}=$ Tinggi; $\mathrm{ST}=$ Sangat Tinggi. Sedangkan derajat kecocokan alternatif-alternatif dengan kriteria keputusan adalah: $\mathrm{T}$ (kecocokan) $\mathrm{S}=\{\mathrm{SK}, \mathrm{K}, \mathrm{C}, \mathrm{B}, \mathrm{SB}\}$, dengan $\mathrm{SK}=$ Sangat Kurang; $\mathrm{K}$ Kurang; $\mathrm{C}=$ Cukup; $\mathrm{B}=$ Baik; dan $\mathrm{SB}=$ Sangat Baik. Fungsi keanggotaan untuk setiap elemen direprentasikan dengan menggunakan bilangan fuzzy segitiga sebagai berikut:

- $\mathrm{SR}=\mathrm{SK}=(0,0,0.25)$

- $\mathrm{R}=\mathrm{K}=(0,0.25,0.5)$

- $\mathrm{C} \quad=(0.25,0.5,0.75)$

- $\mathrm{T}=\mathrm{B}=(0.5,0.75,1)$

- $\mathrm{ST}=\mathrm{SB}=(0.75,1,1)$ 
b. Rating untuk setiap kriteria keputusan yang diberikan oleh pengambil keputusan seperti terlihat pada Tabel 1. Sedangkan derajat kecocokan kriteria keputusan dan alternatif seperti terlihat pada Tabel 2.

Tabel 1. Rating kepentingan untuk setiap kriteria

\begin{tabular}{|c|c|c|c|c|c|}
\hline Kriteria & C1 & C2 & C3 & C4 & C5 \\
\hline Rating Kepentingan & ST & T & C & R & T \\
\hline
\end{tabular}

Tabel 2 . Rating kecocokan setiap alternatif terhadap setiap kriteria

\begin{tabular}{|c|c|c|c|c|c|}
\hline \multirow{2}{*}{ Alternatif } & \multicolumn{5}{|c|}{ Rating Kecocokan } \\
\cline { 2 - 6 } & C1 & C2 & C3 & C4 & C5 \\
\hline A1 & SK & K & SB & SB & C \\
\hline A2 & SB & B & C & B & SK \\
\hline A3 & B & SB & K & B & B \\
\hline
\end{tabular}

c. Dengan mensubstitusikan bilangan fuzzy segitiga ke setiap variabel linguistik ke dalam persaman (2) sampai persamaan (5), diperoleh nilai kecocokan fuzzy seperti pada Tabel 3.

Tabel 3 Indeks kecocokan untuk setiap alternatif.

\begin{tabular}{|c|c|c|c|c|c|c|}
\hline \multirow{2}{*}{ Alternatif } & \multicolumn{5}{|c|}{ Rating kecocokan } & \multirow{2}{*}{ Indeks kecocokan fuzzy } \\
\cline { 2 - 5 } & C1 & C2 & C3 & C4 & C5 & 2 0,$0625 ; 0,2625 ; 0,5500$ \\
\hline A1 & SK & K & SB & SB & C & 0,$1750 ; 0,4000 ; 0,6625$ \\
\hline A2 & SB & B & C & B & SK & 0,$175 ; 0,4750 ; 0,7750$ \\
\hline A3 & B & SB & K & B & B & 0,$2000 ; 0,0$ \\
\hline
\end{tabular}

\section{Langkah 3: Menyeleksi alternatif yang optimal}

a. Dengan mensubstitusikan indeks kecocokan fuzzy pada Tabel 3, ke persamaan (6), dan dengan mengambil derajat keoptimisan $(\alpha)=0$ (tidak optimis), $\alpha=0,5$ dan $\alpha=1$ (sangat optimis), maka akan diperoleh nilai total integral seperti terlihat pada Tabel 4.

Tabel 4 Nilai total integral setiap alternatif.

\begin{tabular}{|c|c|c|c|}
\hline \multirow{2}{*}{ Alternatif } & \multicolumn{3}{|c|}{ Nilai total integral } \\
\cline { 2 - 4 } & $\alpha=0$ & $\alpha=0,5$ & $\alpha=1$ \\
\hline A1 & 0,1625 & 0,2844 & 0,4063 \\
\hline A2 & 0,2875 & 0,4094 & 0,5313 \\
\hline A3 & 0,3375 & 0,4813 & 0,6250 \\
\hline
\end{tabular}

b. Dari Tabel 4, terlihat bahwa A3 memiliki nilai total integral terbesar berapapun derajat keoptimisannya, sehingga lokasi Piyungan akan terpilih sebagai lokasi optimal untuk penempatan pemancar. 


\section{SIMPULAN}

Dari hasil penelitian di atas dapat disimpulkan bahwa dengan mengunakan Fuzzy Multi Criteria Decision Making:

a. Dapat ditetapkan Piyungan sebagai lokasi penempatan pemancar dari 3 alternatif lokasi, dengan 5 kriteria yang diberikan.

b. Piyungan merupakan lokasi optimal yang diperoleh baik dengan derajat keoptimisan 0; 0,5; maupun 1.

\section{PUSTAKA}

Chen, S. H. (1985). Ranking Fuzzy Numbers with Maximizing Set and Minimizing Set. Fuzzy Sets and Systems.

Chang, P. L. dan Chen, Y. C. (1994). A Fuzzy Multi-Criteria Decision Making Method for Technology Transfer Strategy Selection in Biotechnology. Fuzzy Sets and Systems.

Joo, H. M., dan Chang, S. K. (2004). Application of Fuzzy Decision Making Method to the Evaluation of Spent Fuel Storage Options. Korea.

Liou, T. S., dan Wang, M. J. J. (1992). Ranking Fuzzy Numbers with Integral Value. Fuzzy Sets and Systems. 